\title{
PATENT INTERVENTRICULAR SEPTUM (MALADIE DE ROGER)
}

\author{
BY \\ D. C. MUIR, M.D., M.R.C.P., \\ Physician to the Hull Municipal Rheumatism and Heart Clinic. \\ AND \\ J. W. BROWN, 'M.D., M.R.C.P., \\ Physician to the Lindsey Rheumatism and Heart Clinic,
}

Roger ${ }^{1}$ in 1879 was the first to describe a congenital defect of the heart in which symptoms were absent, although definite, constant, and characteristic physical signs were present. An interesting feature of his description was that his observations were unsupported by an autopsy on the case that he described. However, so definite was the syndrome that Dupré $^{2}$, who verified a case at autopsy in 1891, proposed for it the name of ' maladie de Roger.' To this day very little has been added to Roger's description unless it has been by way of confirmation.

As a preface to a discussion of this particular lesion a part of Roger's work may well be quoted ${ }^{19}$. In his conclusions he finds that:-

There is a developmental defect of the heart from which cyanosis does not result in spite of communication between the two ventricular cavities . . . It consists of an opening in the interventricular septum. It is revealed only on auscultation by a physical sign with very definite characters; this is a long loud murmur ... It begins in systole and is prolonged to such an extent as to entirely cover the natural tictac of the heart sounds. It has its maximum intensity not at the apex . . . but over the upper third of the precordial region. It is chiefly medial in position like the septum itself, and from this central position it diminishes in intensity uniformly as one moves the stethoscope over the chest. The murmur is not transmitted to the vessels. It coincides with no other sign of heart disease except a harsh thrill which accompanies it. This murmur is the pathognomonic sign of an interventricular septal defect.

Incidence.-Uncomplicated interventricular septal defects are probably amongst the commonest of all congenital cardiac abnormalities. Unfortunately few statistics are available on this point, for in most published returns of heart disease, such as those provided by school authorities, cases are all grouped together as congenital heart disease without attempt at separation into different anatomical groups. Apart from the more formal statistics, such as those coming from clinics, evidence of the incidence of this abnormality is scanty. This is because the maladie de Roger is so benign and symptomless that many cases never come under observation, and still fewer to autopsy. 
In a series of 119 cases of congenital heart disease in elementary school children described by Perry ${ }^{3}$, if his Groups 1 and 2 are taken together, 42 cases (35 per cent.) may be presumed to be instances of uncomplicated septal defect. As evidence of the benign nature of this defect it is noteworthy that practically all his cases were on full school régime with games and drill. In Abbott's ${ }^{4} 850$ collected cases a defect of the interventricular septum was present 240 times. An associated abnormality was present in 186 cases, so that 54 cases had a septal defect as the primary lesion. In 8 of these cases the aorta over-rode the septal defect, so that pure patency of the interventricular septum occurred 46 times. Laubry and Pezzi ${ }^{10}$ state that pure patency of the septum is rare, and in view of the origin of the defect from arrest of development of the bulbus cordis, suspicion of concomitant pulmonary stenosis must always be aroused. They are inclined to think that the diagnosis is too frequently made. As each of the cases of Abbott has been controlled by autopsy, they have confirmed the work of Roger published many years before.

In the present communication uncomplicated cases only are considered. Cases in which there is dextra-position of the aorta, on account of the large venous arterial shunt that is necessarily present, properly belong to the cyanotic group of congenital cardiac cases. The syndrome of ventricular septal defect, right-sided aorta, and no stenosis of the pulmonary artery, has been named the Eisenmenger complex. It seems probable that a few of the cases described as the maladie de Roger, but with cyanosis, belong to this group.

Pathology. - The defect arises as a fault in development of the bulbar septum which does not descend sufficiently to meet the ventricular septum, and consequently the defect is usually situated at the upper part of the interventricular septum. Letulle has supported the view that patency of the interventricular septum is most frequently the result of a fotal endocarditis, but this view has received very little support.

Usually the defect is very small, admitting only a probe, but sometimes the opening may be large enough to admit the thumb. It is most commonly just anterior to the membranous part of the septum, the undefended space of Peacock, and as it opens immediately beneath the septal cusp of the tricuspid valve the latter structure may occasionally be involved, producing tricuspid insufficiency. Occasionally other parts of the septum may be the site of perforation. In consequence of this communication between the two ventricles there is an arterial venous shunt of blood from left to right. Under some circumstances, notably pulmonary infection, or as a terminal event, reversal of flow may occur with resultant cyanosis (cyanose tardive). Certain observers have recorded cases in which there was permanent cyanosis. These cases would appear to be outside the limits of the disease as defined by Roger, and are probably, as indicated above, the result of dextra-position of the aorta.

Complications.-Patients with this abnormality, as all others with congenital cardiovascular defects, are exposed to the risks of the supervention of an infective endocarditis. The proportion of cases in Abbott's 
series where such an event occurred was 37 per cent., and vegetations when present may be found in the margins of the defect, and on the wall of the right ventricle where the stream of blood passing through the defect impinges. Audibert ${ }^{18}$ and others in recording a recent case of the maladie de Roger where such an event occurred emphasized the great rarity of these cases, and expressed the opinion that the congenital cardiopathies in general, and lesions of the interventricular septum in particular, were not nearly as susceptible to the onslaught of streptococci as healed rheumatic lesions of the valves.

An interesting abnormality described as being associated with defects of the interventricular septum is congenital heart block. Scattered through the literature are numerous references to congenital heart block, and a number of these cases have been attributed to congenital perforations of the interventricular septum, at the site of the undefended space of Peacock which is in intimate relationship with the bundle of His. Such a hypothesis has always been attractive, and has often served to explain the pathology of these cases where no autopsy has been performed. If, indeed, a simple perforation of the interventricular septum at this site were the sole explanation of congenital heart block, then such cases should be common in view of the frequent occurrence of ventricular septal defects either alone, or complicated by other congenital abnormality. In Lampard's ${ }^{5}$ collected series of 31 cases of congenital heart blcck, congenital cardiac lesions were present in 19, and of these 12 were apparently due to a patent interventricular septum. Aitken ${ }^{16}$ has reviewed 39 cases of congenital block, and has found 25 cases in which a patent interventricular septum was reputed to be present. More recently Yater, Lyon, and $\mathrm{McNabb}^{6}$ have reviewed 44 cases of accepted congenital heart block, and of these a patent interventricular septum was present in 26, and complete absence of the septum in one. The relation of the bundle of His and its branches in cases of septal defect has been investigated by Monckeberg. ${ }^{8}$. In general there has been very little change in the normal arrangement of the fibres. Even in extreme types such as the cor biloculare the bundle has been found on the wall of the common ventricle dividing into right and left branches, and in Wilson and Grant's ${ }^{7}$ case of cor biatriatum triloculare the bundle was present in the tag of tissue representing the interventricular septum.

In explanation of the rarity of conduction defects in these cases the site of perforation is important. In septal defects the usual site according to Abbott is ' at the base of the septum just anterior to the pars membranacea.' Further, the work of Monckeberg suggests that development of the cardiac septa takes place after the development of the bundle of His. The rudiments of the bundle are visible at about the fifth week, but the septa are only visible from the seventh to tenth weeks. It thus seems hardly likely that malformations of the septum will interfere with the development of the bundle that has already taken place. On these grounds it may be argued with some justification that however severe a defect may be present, it probably cannot by itself be the cause of congenital heart block. 
Aitken $^{16}$ has suggested that the cause of the heart block may be due to an excessive formation of fibrous tissue between the auricle and ventricle which interferes with the continuity of the bundle. On the above grounds it will be appreciated why cases of congenital heart block are rare in practice. If septal perforations alone were sufficient to cause it, this abnormality would be much more frequent than it is, because septal defects are among the commonest of all congenital heart disorders. No case of heart block has occurred in our series.

On theoretical grounds simple patency of the interventricular septum should not be a serious handicap, apart from the risk of a superadded infective endocarditis. The average duration of life in Abbott's cases was but 14 years, the oldest being 44. In this connection it must be realized that Abbott's cases all came to autopsy. The maladie de Roger is so benign and symptomless that probably only a very small proportion of cases are definitely recognized. Owing to a mistaken idea that the congenital cardiac is necessarily young and cyanotic, and over-emphasis of the doctrine of carditis without arthritis, it is probable that many cases pass through life with a diagnosis of a rheumatic heart, or even mitral regurgitation despite the presence of a clear cut clinical picture.

Symptoms.--There are no symptoms that can be properly attributed to this malformation. Its characteristic feature is absence of symptoms with marked physical signs. Cyanosis does not occur except as a terminal event, or during a severe pulmonary infection. Rarely it has been recorded as occurring on exertion, as, for example, in two cases in Perry's series. It was marked in a case described by Carpenter'. Holding the breath or the use of a spirometer has not induced cyanosis in any of our cases with this lesion. Dyspnoea on exertion is rarely complained of by the patient unless he is suffering from some added complication, or has an over-anxious mother. The condition is absolutely compatible with a normal school life and participation in games and drills.

Physical signs.--The distinctive murmur has been aptly described by Roger. An extract from his description is quoted above. A long harsh mesocardial murmur occupying the whole of systole, and sometimes slightly prolonged into diastole, with maximum intensity in the third and fourth left interspaces close to the sternum, is the characteristic physical sign. The murmur is conducted with diminishing intensity towards the apex and left clavicle. It may be heard in the neck in a few cases. Frequently it may be heard in the left side of the back, particularly in the left inter- and infra-scapular regions. Its important characteristic is its dimunition in intensity as the periphery of the praecordium is approached. In a few cases there is no definite point of maximum intensity of the bruit; or it may be heard best as high as the second rib and interspace, or low down the left sternal border. In about a third of the cases (15 in 46 cases in Abbott's series), there is an accompanying systolic thrill which may be diffuse, or localized to the point of maximum intensity of the bruit. The thrill may 
best be felt, and occasionally only felt with the subject in ventral decubitus. Laubry and Pezzi ${ }^{10}$ have described a certain character of the first sound of the heart recalling the first sound in mitral stenosis. The pulmonary second sound is as a rule unaltered, but hypertension in the pulmonary circuit may lead to its accentuation or reduplication.

Certain cases are on record (Parkes Weber ${ }^{21}$, French ${ }^{22}$, Stamm $^{23}$ ), in which a thrill and systolic bruit present in early childhood have quite disappeared with the growth of the child. Such a disappearance of physical signs could be explained on the grounds that a lesion of the interventricular septum in a small child may be considerable in relation to the size of the heart and the whole body. If the defect does not enlarge in proportion as the child grows, it may become so small as to be negligible and give rise to no physical signs. Weber also states that occasionally septal, defects are surrounded by considerable fibrous tisue which may contract. Bard ${ }^{20}$ discussing lesions of the interventricular septum states that the murmur may be absent when pressure within the right ventricle is the same as to that in the left, and consequently there is no flow of blood from left to right.

Radiology.-There is some confusion in the literature as regards the radiological appearance in this condition. This confusion has probably arisen in relation to the degree of the defect. A large defect is a priori more likely to produce changes in the outline of the heart than a small one. Vaquez and Bordet ${ }^{11}$ described in certain cases a general increase in the size of the heart as a whole, so that the heart projects on both sides of the midsternal line, and appears more or less rounded or globular. They noted vigorous and synchronous pulsation of both borders of the heart shadow. They did not find these changes to be constant: in fact, in certain of their cases there was no apparent alteration in the size and contour of the heart. Laubry and Pezzi ${ }^{10}$ describe a similar heart outline in some cases. They, like Vaquez and Bordet, find that there is no abnormality of the vascular arcs. Laubry ${ }^{12}$ has later taken up the position that the cardiac contour is as a rule unchanged from normal. Deneke ${ }^{13}$ described a globular heart with a spherical pump-like action. Pulsations of abnormal amplitude, visible and synchronous on both right and left borders, takes place. This is, however, of doubtful diagnostic value, for it may be seen in normal children or young adults with a vigorously acting heart. All observers would seem to agree that there is no abnormality of the vascular arcs. The general consensus of opinion appears to be that there is no characteristic and distinctive modification of the cardiac silhouette in this condition. If, however, decompensation sets in, there are suggestive changes in the contour, according to which side of the heart is particularly involved. A large globular heart should always be considered in the light of a ventricular septal defect.

The electrocardiogram is physiological. There may be an increased amplitude of the QRS complexes such as may occur in any other congenital cardiac lesion, 
Diagnosis.-There should be very little difficulty in diagnosis as the murmur is characteristic. Points in favour of the diagnosis other than this typical bruit are the absence of any cardiac symptoms, or of a history of rheumatic infection past or present. The bruit is typically mesocardial, is long and harsh with maximum intensity in the third and fourth left spaces close to the sternum. It diminishes in intensity as the periphery is approached.

In cases with a patent ductus arteriosus, the murmur is typically of a continuous or machinery character, maximum in the second left space, with dilatation of the pulmonary artery evidenced by Gerhardt's dullness and by radiological examination. In young subjects with a patent ductus the bruit may be systolic in time, but its maximum intensity is always in the second left interspace, and again evidence of dilatation of the pulmonary artery is forthcoming (Muir and Brown ${ }^{15}$ ).

In pulmonary stenosis cyanosis may not appear until late and the case be quite symptomless. The bruit is entirely systolic in time, maximum in the second left space, with modification of the pulmonary second sound which is diminished or absent. Radiological examination shows fullness of the pulmonary arc.

From septal defects complicated by dextra-position of the aorta, distinction is made by the early appearance of cyanosis and the prominence of dyspnoea. Similarly in the tetralogy of Fallot cyanosis, clubbing, and dyspnoea are present; the bruit is conducted into the carotids, and there is a characteristic radiological picture $\left(\mathbf{P a p p}^{14}\right)$.

In tricuspid insufficiency, which may be associated with a septal defect, the murmur is loudest to the right of the sternum, the right side of the heart is dilated and the liver is enlarged. Cardiac failure is early and prominent.

Functional or haemic murmurs are best heard at the apex or over the pulmonary artery. They are soft and blowing, and tend to vary with the phase of respiration and the position of the subject.

From rheumatic heart disease diagnosis is made by the absence of history of rheumatic infection, arthritis or chorea. The youth of the subject and the early recognition of the heart lesion may often be helpful points in coming to a decision. In rheumatic disease of the mitral valve the bruit is loudest at the apex and is conducted to the axilla. There is also modification of the heart sounds. The systolic bruit is not so prolonged and has nct the elective localization of the bruit of a septal defect.

Treatment.-Roger in his original publication naively writes:-

An exact diagnosis in heart disease ordinarily demands an active and persistent treatment. If, on the other hand, there is a congenital malformation of the heart vigorous treatment is useless and even harmful. To show, thanks to precision in diagnosis, when to act in one case, and refrain in another is to render a service not only to physicians but also to patients ${ }^{19}$.

Little may be added to this. These cases require no treatment other than abstention from coddling and the careful eradication of any septic 
focus that may be present. These children should be allowed to live a perfectly normal life unrestricted. Accurate diagnosis and careful explanation of the nature of the disorder will go a long way to reassure parents and patient, and prevent the development of a cardiac invalid.

\section{Authors' series.}

In our present series of 100 cases of congenital heart disease in elementary school children, 40 appear to have a patent interventricular septum as their sole abnormality. In arriving at a diagnosis we have adhered strictly to the clinical description of Roger, and have employed subsidiary methods of investigation to exclude other possible malformations. In all cases teleroentgenograms have been taken and some have been examined under the screen. In view of the youth of our patients, and their dislike to being in the dark, the former method is our method of choice, although it is open to some objection on the ground of accuracy. In a few cases electrocardiograms have been taken. We have accepted as the essential points in diagnosis the symptomless nature of the malady, and its marked physical signs. We have interpreted a harsh, prolonged, mesocardial systolic murmur of maximum intensity in the third and fourth left interspaces close to the left sternal margin as the capital physical sign. This bruit is so characteristic that, once appreciated, it need never be confused with other bruits, particularly with those of a functional or haemic character.

Sex and age.- Of our 40 cases 25 are females and 15 are males. We can offer no adequate explanation of the apparent preponderance of females, but we find that in our whole series of congenital cardiac cases the female cases are somewhat in excess. There are 54 per cent. females in the whole series, but this does not explain the percentage of 62.5 females in the series under discussion. The youngest is a male aged nine months, and the oldest a male of 14 years. The first intimation of the presence of a cardiac lesion was at the routine school entrance examination in 28 cases. Of the remainder, in only 1 case was the lesion recognized at birth. In 11 cases the abnormality was discovered during some illness, such as influenza, measles or pneumonia. The early recognition is of some importance in diagnosis because the main incidence of rheumatic carditis is after the age of 5 years, and hence the earlier the age of detecticn of a cardiac lesion, the more likely it is to be of congenital origin.

Associated abnormalities.-Two cases were mongols, and 1 case had an absent xiphisternum. We have been particularly careful to search for associated developmental defects in these cases and have been struck by their rarity.

Symptoms. - Two cases were said to have been blue babies at birth. One case, which was said to have ' attacks,' probably was suffering from minor epilepsy. The large proportion of these cases are quite devoid of symptoms referable to a cardiac condition. One case complained of 


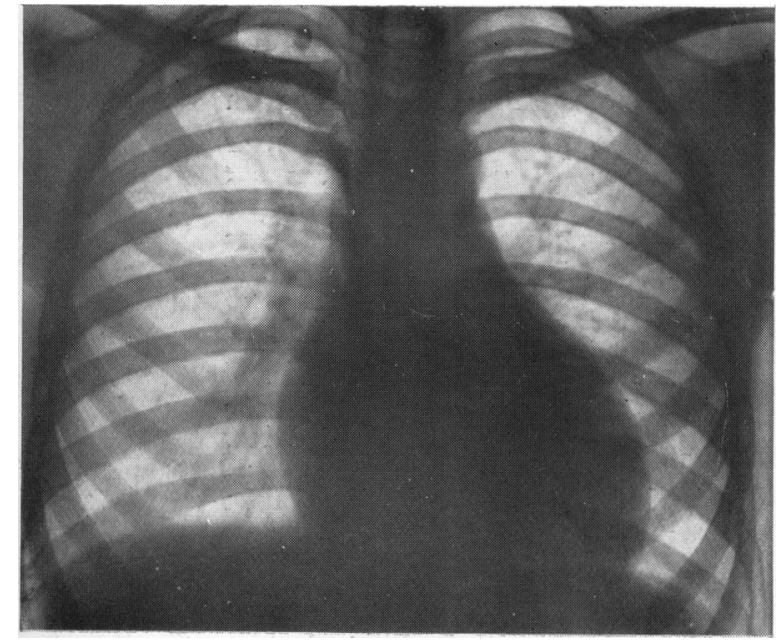

FIG, 1.

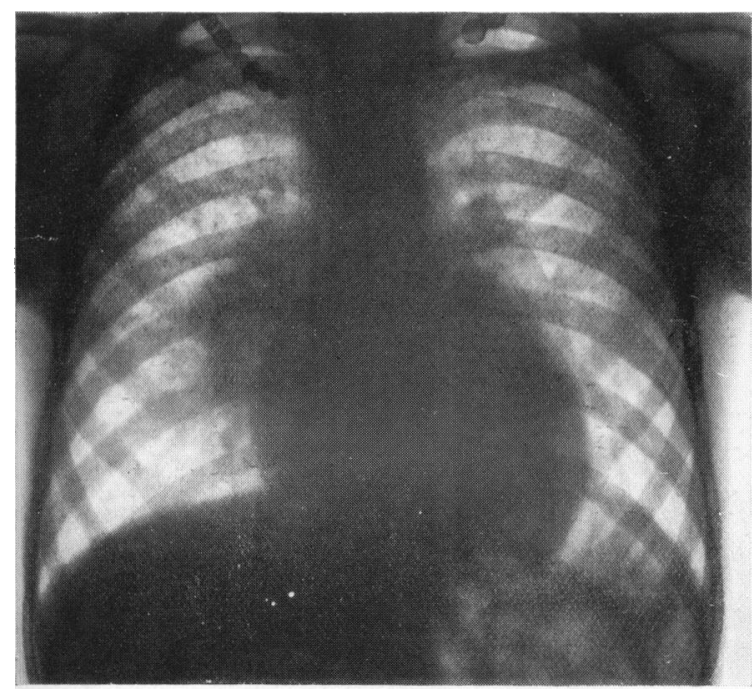

Fig. 3.

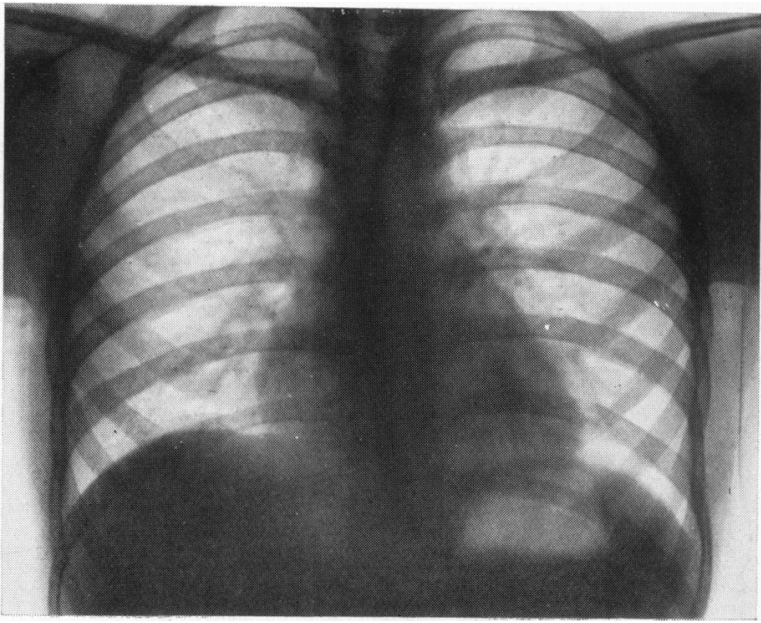

FIG. 2.

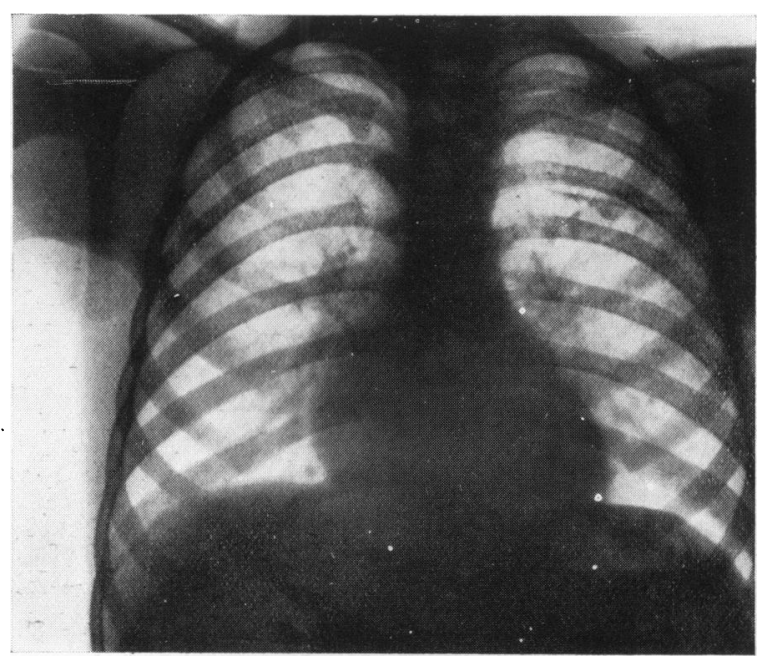

FIG. 4.

The heart in the maladie de Roger. Skiagrams of typical cases showing a globular contour. 


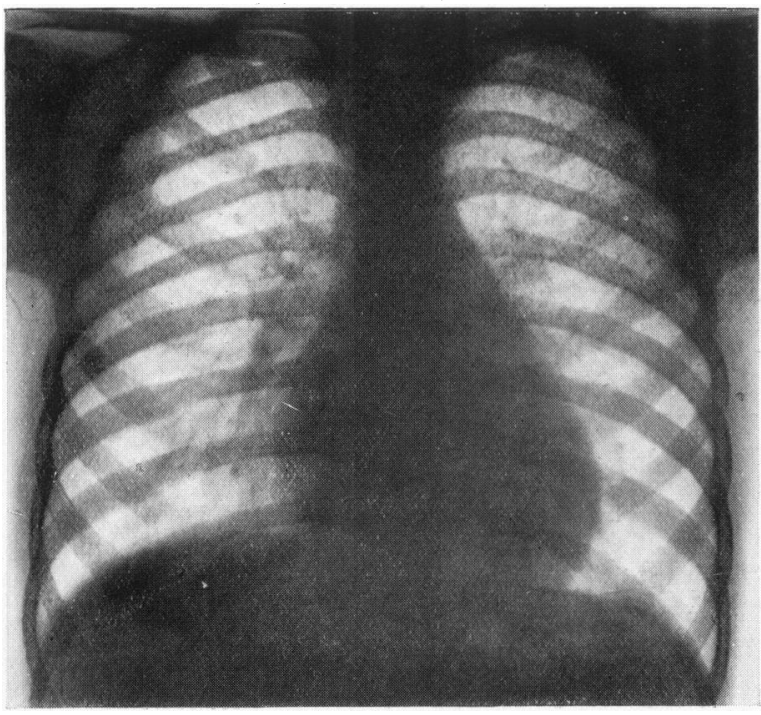

FIG, 5.

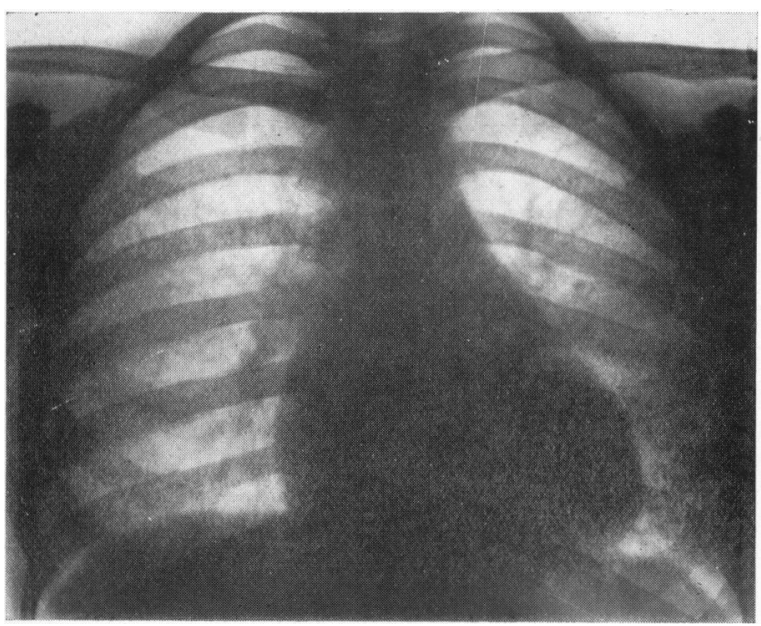

FIG. 7.

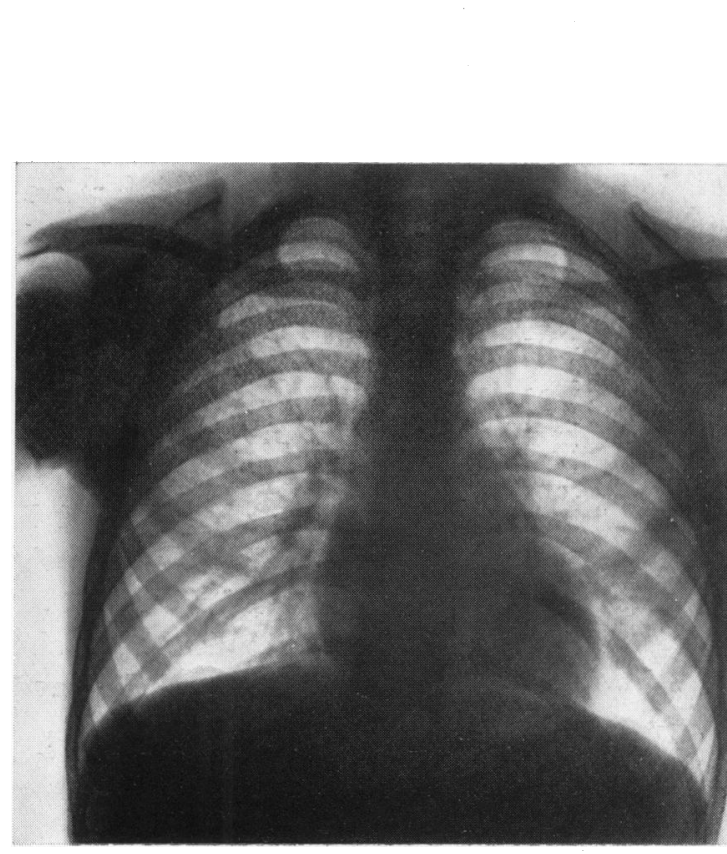

FIG, 6.

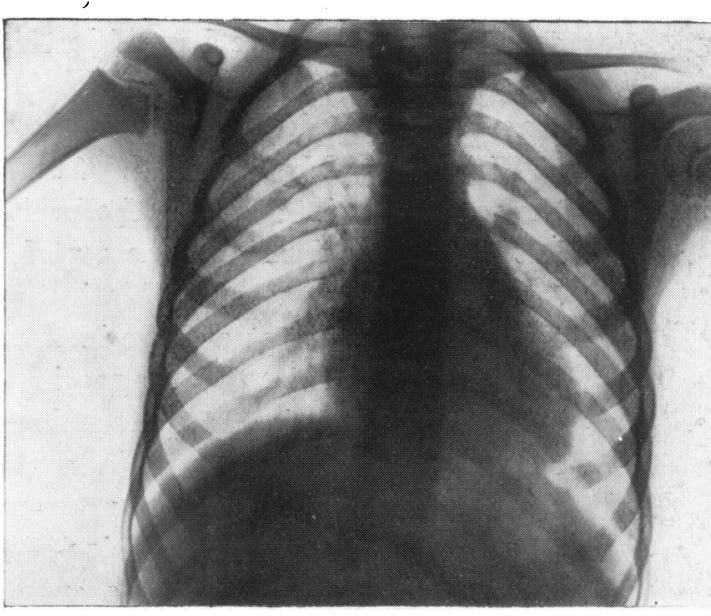

FIG, 8 .

The heart in maladie de Roger. Typical cases with a straight left border. 
dyspnoea on exertion, and another of palpitation. We find it difficult to assess the importance of these symptoms in children, because some of the symptoms are occasionally due to a dislike of the school that they are attending, and clear up with a change of school. Cyanosis appears in the histories of 5 of these cases, and in only 2 cases does it appear to have been important. In one case, the child was for a period the colour of Reckitt's blue. This cleared up, and this child who is seen regularly is now quite devoid of cyanosis, and presents the typical clinical picture of Roger's disease with no radiological abnormality. In another case cyanosis on exertion was sufficient to call for remark by her parents, but such cyanosis has never been reproduced in the clinic. In the others cyanosis has only been transient and occurring with respiratory infection. As far as could be ascertained there is no increased liability of these children to respiratory infection. All the children were weighed and measured and their heights and weights were compared with normal standards for school children. Twelve of the children were definitely above the average development, 18 were average, and only 10 were below average.

Physical signs.-A loud harsh prolonged systolic bruit was present in all of the cases. In 15 it was maximum in the third left interspace close to the sternum, in 20 in the fourth left space, and in 4 low down between the apex and the left sternal border. In one case where the murmur was loud in front it was definitely louder in the left interscapular region behind. There was no evidence in this case of a coarctation of the aorta. In 12 of the cases the murmur was audible in the left side of the back. We have not followed the example of Perry $^{3}$ and segregated these latter cases into a separate group as we have felt that fundamentally they all belong to the same group. It seems possible that the site of perforation of the septum may affect the distribution of the murmur. This is suggested by the case of Weiss quoted by Abbott ${ }^{17}$. Similarly, we have thought in 4 cases in which the maximum intensity of the bruit was midway between the apex and the left sternal border, that the septal perforation was abnormally placed. In 5 cases the bruit was audible in the carotids. It has been generally stated that the bruit is not audible in the neck, and that audibility in the neck is a capital point in the diagnosis of the tetralogy of Fallot. In a pure pulmonary stenosis the systolic bruit is not heard in the carotids, whereas the coincident presence of a septal defect with over-riding of the aorta renders conduction of the murmur to the neck possible. None of these 5 cases show any dextra-position of the aorta radiologically, or any cyanosis. In 13 cases ( 32 per cent.), a systolic thrill was present and its maximum intensity was at the site of maximum intensity of the bruit. In 2 cases the thrill was present at the first examination, but not on examination at a later date.

Radiology.-All our cases have undergone X-ray examination. We have as a routine taken teleroentgenograms of these children at a distance of seven feet. We have found this method preferable for reasons indicated 
above. Radiological examination has failed to disclose any typical constant cardiac contour which might justly be said to be characteristic of the maladie de Roger. In a large number of cases the heart outline has appeared to be quite normal, and in only 12 cases could the heart be said to approach a globular contour (Figs. 1, 2, 3, and 4). The pulmonary arc is full in certain instances, giving a rather straight left cardiac border (Figs. 5, 6, 7, 8). In the cases examined with the fluorescent screen, the vigorous spherical pumplike action of the heart, described by Deneke, was not consistently seen. Our impression is that such vigorous synchronous contraction of both borders of the heart can be seen not infrequently in children with apparently normal hearts. Particular attention has been paid to the vascular arcs in a search for dextra-position of the aorta and right aortic arch.

We have found the $\mathrm{X}$-ray examination of most value in excluding other congenital cardiac conditions.

\section{Summary.}

(1) A study has been presented of 40 cases in which the physical signs pointed to a diagnosis of the maladie de Roger.

(2) Evidence has been brought forward which seems to indicate that this condition is much commoner than is generally recognized. A proper appreciation of the physical signs as described by Roger would lead to the more frequent identification of this defect.

(3) In the present series there was no case of heart block or of infective endocarditis. The suggestion is put forward that a lesion of the interventricular septum per se is not the whole cause of congenital heart block.

(4) Permanent cyanosis is not a part of the clinical picture of the maladie de Roger. When cyanosis is permanently present it is due to some accompanying structural abnormality.

(5) There is no characteristic radiological picture of the maladie de Roger.

Our thanks are due to Dr. Morrison and the Assistant Medical Officers of the Hull School Medical Service, and to Dr. Southey, of the Grimsby School Medical Service, for referring these cases to us; and to Dr. Bannen and Mr. S. V. Dolby for the radiograms.

\section{REFERENCES.}

1. Roger, H., Bull. de l'Acad. de Med., Paris, 1879, VIII, 1074.

2. Dupré, E., Bull. de Soc. Anat. de Paris, Paris, 1891, 5 ser., V, 404.

i. Perry, C. B., Arch. Dis. Childh., Lond., 1931, VI, 265.

4. Abbott, M., Modern Medicine, 3rd Ed., Lond., 1927, IV.

5. Lampard, M. E., Arch. Dis. Childh., Lond., 1928, III, 212.

6. Yater, W., McNabb, P., \& Lyon, J., J. Am. Med. Ass., Chicago, 1933, C, 1831.

7. Wilson, J., \& Grant, R. T., Heart, Lond., 1925-6, XII, 295.

8. Monckeberg, Handb. d. Spez. Anat. u. Histol., Berlin, 1924, XI, 290.

9. Carpenter, G. L., Rept. Soc. Dis. Child., Lond., 1906, VI, 165. 
10. Laubry, C., \& Pezzi, C., Maladies Congenitales du Coeur, Paris, 1921.

11. Vaquez, H., \& Bordet, E., Radiologie du Coeur, Paris, 1928, 192.

12. Laubry, C., Nouveau Traite de Pathologie Int., Paris, 1930, IIf.

13. Deneke, Deutsch. Arch. f. Klin. Med., 1906, LXXXIX, 79.

14. Papp, L., Arch. Malad. Coeur, Paris, 1931, 249.

15. Muir, D. C., \& Brown, J. W., Arch. Dis. Childh., Lond., 1932, VII, 291.

16. Aitken, J., Lancet, Lond., 1932, ii, 1375.

17. Abbott, M., Blumer's Bedside Diagnosis, Lond., 1929, II, 428.

18. Audibert, V., et al., Bull. Soc. Med. Hop., Paris, 1933, 7.

19. White, P. D., Translation in Heart Disease, N.Y., 1931.

20. Bard, L., Arch. Malad. du Coeur, Paris, 1921, 212.

21. Weber, P., Brit. J. Child. Dis., Lond., 1918, XV, 113.

22. French, H., Guy's Hosp. Gaz., Lond., 1918, XXXII, 87.

23. Stamm, L., Loc. cit., 146. 